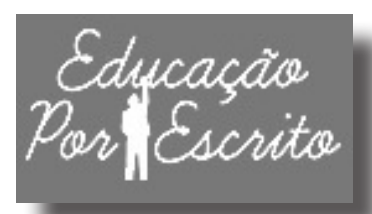

ARTIGO

\section{Editores}

Maria Inês Côrte Vitoria PUCRS, RS, Brasil Pricila Kohls dos Santos PUCRS, RS, Brasil

\section{Equipe Editorial}

Rosa Maria Rigo

PUCRS, RS, Brasil

\title{
A articulação entre a autoavaliação e os processos de planejamento em instituições de educação superior no estado do Río Grande do Sul
}

\author{
The interaction between the self-assessment and planning processes \\ in higher education institutions in Rio Grande do Sul state
}

\author{
Giovana Fernanda Justino Bruschia, Alam de Oliveira Casartellib
}

\section{RESUMO}

Uma gestão consistente que proporcione qualidade e sustentabilidade nas Instituições de Educação Superior (IESs) é o que vem provocando debates no segmento educacional. A preocupação com resultados relativos ao Sinaes (Sistema Nacional Avaliação da Educação Superior), desenvolvidos pelo Ministério da Educação, é um dos pontos importantes desse processo. Uma das obrigações contidas no Sinaes é o estabelecimento da CPA (Comissão Própria de Avaliação), a qual tem a finalidade de conduzir as avaliações internas em uma IES. As autoavaliações têm papel fundamental no desenvolvimento e melhorias nas instituições e, dessa forma, merecem destaque se usadas de forma efetiva como insumos para o planejamento da organização. O presente estudo tem a finalidade de identificar como ocorre a articulação entre os resultados das autoavaliações e os processos de planejamento em IESs. Para tanto, foram realizadas entrevistas com gestores e coordenadores responsáveis pela CPA e pelo Planejamento Estratégico ou PDI - Plano de Desenvolvimento Institucional. As declarações dos entrevistados demonstraram que todos estão conscientes da importância de existir articulação entre a autoavaliação e os processos de planejamento. Contudo, não há relatos de uma metodologia, em nenhuma instituição, que determine um padrão de aplicação dessas atividades sincronizadas, ou seja, a articulação é feita conforme a necessidade, por meio da entrega de relatórios para a reitoria e aos coordenadores.

Palavras-chave: Sinaes; Autoavaliação; Planejamento.

\footnotetext{
a Mestrado em Gestão Educacional pela Universidade do Vale do Rio dos Sinos. Especialização em Administração da Produção, Gestão da Qualidade, MBA em Gestão em Marketing e Graduação em Letras. Professora do MBA de Gestão de Pessoas e no MBA em Gerência Empresarial.

b Possui Graduação em Administração de empresas, Mestrado em Gestão Empresarial e Doutorado em Comunicação Social. É Pró-Reitor de Administração e Finanças da Pontifícia Universidade Católica do Rio Grande do Sul. Tem experiência nas áreas de Administração, Gestão universitária, Educação e Marketing político. É professor do Programa de Pós-Graduação em Educação da PUCRS. Atua também como avaliador Institucional do MEC.
}

Este artigo está licenciado sob forma de uma licençą
Creative Commons Atribuicăo 4.0 Internacional, Creative Commons Atribuição 4.0 Internacional, que permite uso irrestrito, distribuição e reproduçăo
em qualquer meio, desde que a publicaçăo origina seja corretamente citada.
http://creativecommons.org/licenses/by/4.0/deed.pt_BR 


\section{ABSTRACT}

A consistent management to provide quality and sustainability in Higher Education Institutions (HEI) is what has led to debates in the educational segment. Concern about results for the Sinaes (National System Higher Education Evaluation) developed by the Ministry of Education is one of the important points of this process. One of the obligations contained in Sinaes is the establishment of the CPA (committee for assessment), which aims to conduct internal assessments in an HEI. The self-assessments play a fundamental role in the development and improvements in institutions and thus worth mentioning if used effectively as inputs for planning the organization. Thus, this study aims to identify how is the relationship between the results of self-assessments and planning processes in HEI. To this end, interviews were conducted with managers and coordinators responsible for CPA and the Strategic Planning or PDI - Institutional Development Plan. The statements of demonstrated interviewed everyone is aware of the importance on existing links between self-assessment and planning processes, however, there are no reports of a methodology, in any institution, to determine a standard for implementing these synchronized activities, joint is made as needed, through the delivery of reports to the rectory and the coordinators.

Keywords: Sinaes; Self-assessment; Planning.

\section{Introdução}

ensino superior no Brasil tem crescido de forma significativa nos últimos anos, e o desenvolvimento econômico do país, a partir dos anos 2000, possibilitou o acesso das classes sociais antes menos favorecidas a esse nível de educação. Em consequência, cresceu o número de instituições privadas e, portanto, aumentou o número de vagas ofertadas, potencializando a concorrência entre as Instituições de Educação Superior (IESs).

O governo federal, diante do crescimento do ensino superior no país, percebeu ser necessário um acompanhamento mais efetivo das IESs e intensificou as ações de regulação, avaliação e supervisão institucional. O Sistema Nacional de Avaliação da Educação Superior (Sinaes) foi criado exatamente para servir como avaliação das IESs e dos cursos de graduação, sejam eles bacharelado, licenciatura ou técnico de nível superior. Esse processo de avaliação produz conceitos baseados em indicadores específicos e tem a finalidade de medir a qualidade das instituições (BRASIL, 2004).

As avaliações tratam de um balanço complexo em que intervêm os recursos de análise, mas também os valores pedagógicos e educativos, o sentido proativo e o envolvimento democrático da comunidade na forma de agentes 
sociais com funções públicas (DIAS SOBRINHO, 1995). Também para Schwartzman (2005), os exames são a culminação de sistemas permanentes de coordenação e acompanhamento e de inspeções das escolas, que procuram garantir não somente que a qualidade da educação seja mantida, mas que todos os estudantes tenham acesso ao mesmo tipo de ensino.

Criado pela Lei no 10.861, de 14 de abril de 2004, o Sistema Nacional de Avaliação da Educação Superior (Sinaes) é formado por três componentes principais de avaliação: das instituições, dos cursos e do desempenho dos estudantes, também conhecido como Enade (Exame Nacional de Desempenho de Estudantes).

O agrupamento das dimensões em cinco eixos visa a facilitar o diálogo entre as atividades que devem ser articuladas no momento da avaliação. Os eixos ficam dispostos (BRASIL, 2014) conforme detalhamento a seguir.

Eixo 1 - Planejamento e Avaliação Institucional: considera a dimensão 8 do Sinaes (Planejamento e Avaliação). Inclui também um relato institucional, que descreve e evidencia os principais elementos do seu processo avaliativo (interno e externo) em relação ao Plano de Desenvolvimento Institucional (PDI), incluindo os relatórios emanados pela Comissão Própria de Avaliação (CPA) do período que constituiu o objeto de avaliação.

Eixo 2 - Desenvolvimento Institucional: contempla as dimensões 1 (Missão e o Plano de Desenvolvimento Institucional) e 3 (Responsabilidade Social da Instituição) do Sinaes.

Eixo 3 - Políticas Acadêmicas: abrange as dimensões 2 (Políticas para o Ensino, Pesquisa e Extensão), 4 (Comunicação com a Sociedade) e 9 (Políticas de Atendimento aos Discentes) do Sinaes.

Eixo 4 - Políticas de Gestão: compreende as dimensões 5 (Políticas de Pessoal), 6 (Organização e Gestão da Instituição) e 10 (Sustentabilidade Financeira) do Sinaes.

Eixo 5 - Infraestrutura Física: contempla a dimensão 7 do Sinaes (Infraestrutura Física).

A Avaliação Institucional é constituída de duas fases: a autoavaliação, coordenada pela Comissão Própria de Avaliação (CPA), orientada por diretrizes específicas; e a avaliação externa, realizada por comissões designadas pelo Inep (Instituto Nacional de Estudos e Pesquisa), tendo como referência os padrões de qualidade para a educação superior, expressos nos instrumentos de avaliação. O processo de avaliação externa, independentemente de sua abordagem, orienta-se por uma visão multidimensional, que busca integrar suas naturezas formativas e de regulação numa perspectiva de globalidade.

As autoavaliações, sob responsabilidade da CPA, têm papel fundamental no desenvolvimento, crescimento e melhorias nas instituições e, se usadas de forma efetiva, constituem-se em importantes insumos para o planejamento. 
Tanto as ações de avaliação interna (autoavaliação) como externa devem realizar-se de forma combinada e complementar. Em ambas, deve haver plena liberdade de expressão e comprometimento com a busca do rigor e da justiça (BRASIL, 2009, p. 111).

Para Dias Sobrinho (2008), como sistema coerente e coeso, o Sinaes estabelece a necessidade de articulação entre as diversas dimensões educativas e institucionais, diferentes metodologias, procedimentos, objetos e objetivos, instâncias da comunidade acadêmico-científica e do Estado, autoavaliação e avaliação externa, bem como autorregulação e regulação.

Para a gestão da IES, a importância da avaliação institucional é inquestionável, especialmente se considerar a responsabilidade estratégica e operacional de dar uma direção à instituição, alinhada com a missão, visão, valores e prestação de contas para a sociedade. Nesse contexto, a Comissão Própria de Avaliação (CPA) surge como uma possibilidade de constituir uma apreciação transparente e fidedigna por parte das IESs, promovendo uma reflexão sobre seus pontos fortes, pontos fracos e oportunidades de melhorias.

Com base em resultados de avaliações conduzidos pela CPA e utilizando metodologias de planejamento, as IESs podem melhorar sua qualidade. Possuir uma prática de gestão que alinhe processos de avaliação e planejamento é uma forma de ação sincronizada, que evidencia um amadurecimento da instituição no que tange ao aprimoramento de sua gestão. Executar simplesmente a autoavaliação sem dar continuidade à proposição de ações de melhorias da IES pode representar uma atitude descuidada e indiferente diante das perspectivas dos alunos e demais partes interessadas. A utilização, portanto, de resultados da autoavaliação como ferramenta efetiva durante o planejamento significa que a IES preocupa-se com o seu desenvolvimento.

Dessa forma, compreender como ocorre a articulação entre a autoavaliação nas IESs e os processos de planejamento torna-se importante, pois os resultados provenientes da CPA devem alimentar o processo contínuo de aperfeiçoamento da qualidade das instituições, contribuindo para a tomada de decisão de seus gestores e apoiando no planejamento de ações e projetos estratégicos. Assim, neste artigo, investigou-se como os processos de avaliação e de planejamento ocorrem nas IESs, identificando-se se existe articulação entre a autoavaliação e o planejamento e se os resultados da autoavaliação oferecem subsídios para a melhoria de qualidade.

O presente artigo está organizado da seguinte forma: além da introdução, o capítulo 2 discute a avaliação do ensino superior e o Sinaes, bem como o novo instrumento de avaliação institucional, o qual apresenta indicadores relativos à necessidade de articulação entre avaliação e planejamento. Na sequência, apresenta-se o processo de planejamento em Instituições de Educação Superior. No capítulo 3, os procedimentos metodológicos utilizados na pesquisa são apresentados. Os resultados são discutidos no capítulo 4 e, por fim, as considerações finais são destacadas. 


\section{Processo de avaliação e planejamento nas IESs}

De acordo com o artigo 209 da Constituição Federal, o governo é responsável pela avaliação das IESs, e o ensino pode ser livre à iniciativa privada, desde que avaliada sua qualidade pelo poder público. Atendendo a esse dispositivo e diante da demanda reprimida, o governo possibilitou maior inserção da iniciativa privada na educação superior, deparando-se com o desafio de como gerir um sistema educacional de proporções maiores, com necessidades de regulação e avaliação de qualidade.

O Ministério da Educação, depois de várias alternativas de avaliação implantadas, criou, em 2004, o Sinaes. Regulado pela Lei no 10.861, de 14 de abril de 2004, o Sistema Nacional de Avaliação da Educação Superior é formado por três componentes principais de avaliação: das instituições, dos cursos e do desempenho dos estudantes, também conhecido como Enade. O Sinaes avalia aspectos relacionados ao ensino, à pesquisa, à extensão, à responsabilidade social, ao desempenho dos alunos, à gestão da instituição, ao corpo docente, às instalações, entre vários outros (BRASIL, 2004). Representa o amadurecimento de um processo histórico de preocupação com a avaliação da qualidade da educação superior.

Catani, Oliveira e Dourado (2001) argumentam que os processos sistemáticos de avaliação universitária, adotados pelo Estado brasileiro, nas últimas décadas, apesar da variedade de mecanismos, sempre estiveram atrelados a uma visão estatal de controle e cobrança de resultados. Assim, aproximaram-se mais de um regulatório mecanismo de prestação de contas das instituições quanto ao uso adequado dos recursos do que de um processo de avaliação que privilegiasse a melhoria do sistema. Conforme Zainko (2008), a proposta de avaliação em caráter mais sistematizado, no Brasil, remonta ao início da década de 1960, quando o governo militar, que vigorou no país, de 1964 a 1985, a título de modernização, submete a educação a um modelo produtivista de eficiência. O grupo de trabalho que propôs a Reforma Universitária de 1968 realizou um amplo diagnóstico, concluindo pela necessidade de incrementar o número de matrículas na educação superior, acompanhando a tendência vigente em outros países de um fenômeno chamado de massificação. Tem início, assim, a expansão da educação superior, com um aumento significativo de instituições e de matrículas, sem que com isso fosse assegurada a democratização do acesso com garantia de permanência e qualidade.

A partir da década de 1990, observa-se que a avaliação da educação superior teve destaque, uma vez que houve uma evolução nos mecanismos e procedimentos adotados. Vários instrumentos e grupos de trabalho sobre a avaliação da educação superior foram, a partir de então, instituídos. Entre estes, destaca-se o Programa de Avaliação da Reforma Universitária (Paru), de 1983; a Comissão Nacional de Reformulação da Educação Superior, conhecida como a Comissão de Notáveis, de 1985; o Grupo Executivo para a Reforma da Educação Superior (Geres), de 1985; o Paiub, primeiro programa de avaliação institucional da universidade brasileira, de 1993; o Exame Nacional de 
Cursos, que ficou popularmente conhecido como Provão; e, por fim, o Sistema Nacional de Avaliação da Educação Superior (Sinaes), de 2004.

Ao promover a avaliação de instituições, de cursos e de desempenho dos estudantes, o Sinaes deve assegurar:

a) Avaliação institucional, interna e externa, contemplando a análise global e integrada das dimensões, estruturas, relações, compromisso social, atividades, finalidades e responsabilidades sociais das instituições de educação superior e de seus cursos;

b) O caráter público de todos os procedimentos, dados e resultados dos processos avaliativos;

c) O respeito à identidade e à diversidade de instituições e de cursos;

d) A participação do corpo discente, docente e técnico-administrativo das instituições de educação superior e da sociedade civil, por meio de suas representações.

A proposta do Sinaes é constituir uma avaliação sistêmica e focada nas IESs que consiga realizar ao mesmo tempo as funções de avaliação e de regulação. Independentemente de sua natureza jurídica e de seus propósitos, as IESs precisam ser entendidas como instituições sociais e, enquanto tais, devem ser avaliadas periodicamente (DIAS SOBRINHO, 2010).

Com relação ao papel das avaliações externas, segundo o autor, estas fazem parte da arquitetura global da avaliação. Contudo, argumenta que não podem sufocar as práticas de diálogo e questionamentos próprios da avaliação institucional participativa, que fazem das instituições espaços públicos de debates e reflexões. Para Dias Sobrinho, a lei do Sinaes é galgada em índices precisos, os quais podem trazer uma falta de aprofundamento de questões mais humanas e sociais e de construção coletiva. Contempla, através de índices, a análise global e integrada de dimensões, estruturas, relações, compromisso social, atividades, finalidades e responsabilidade social, contando com a participação do corpo discente, técnicos administrativos e sociedade civil através de suas representações. A obsessão pela objetividade não deve apagar as questões que restam ser respondidas depois que os índices classificaram os níveis de qualidade e fecharam qualquer possibilidade de questionamento e reflexão (DIAS SOBRINHO, 2008). Nesse sentido, os instrumentos de avaliação têm sido aprimorados ao longo do tempo, objetivando um processo avaliativo mais eficaz, embora passíveis ainda de críticas.

Ao se tratar de avaliação externa, em janeiro de 2014, a Portaria no 92 aprovou os indicadores do Instrumento de Avaliação Institucional Externa para os atos de credenciamento, recredenciamento e transformação de organização acadêmica, modalidade presencial, do Sistema Nacional de Avaliação da Educação Superior. O novo instrumento (BRASIL, 2014) visa a garantir, no processo avaliativo, uma apreciação das condições de oferta das instituições de educação superior e a qualidade como referencial básico dos processos de regulação e supervisão da educação superior, mantendo a concepção do instrumento como matricial, que considera as especificidades das diferentes 
organizações acadêmicas, com foco no Plano de Desenvolvimento Institucional (PDI) e nos processos de Avaliação Institucional (interna e externa).

Por sua vez, nos processos de avaliação interna, nos termos do artigo 11 da Lei no 10.861/2004, a qual institui o Sinaes, toda instituição de educação superior, pública ou privada deverá constituir a Comissão Própria de Avaliação (CPA), com as atribuições de conduzir os processos de avaliação internos da instituição, sistematizar e prestar as informações solicitadas pelo Inep. Além de ser constituída por ato do dirigente máximo da instituição e assegurada a participação de todos os segmentos da comunidade universitária e da sociedade civil organizada (BRASIL, 2004).

Dessa forma, um dos papéis da CPA é analisar os relatórios de autoavaliação e fazer destes uma ferramenta efetiva de melhorias. "Os resultados das avaliações realizadas pela CPA e pelo Inep devem alimentar o processo contínuo de aperfeiçoamento do desempenho da IES e servem como ferramenta para o planejamento de ações de melhoria permanente da qualidade e pertinência das atividades desenvolvidas" (SCAGLIONE, 2011, p. 53). O foco da avaliação está na contínua qualificação da formação acadêmica e profissional e da missão da instituição (SINAES, 2009). Na análise de Creutzberg e Casartelli (2014), o conjunto de dados analisados deve gerar relatórios objetivos, consistentes e confiáveis, a fim de subsidiar a tomada de decisão. Segundo os autores, atender a esse aspecto em todas as instâncias da universidade ainda constitui um desafio e um tópico a ser aperfeiçoado. O trabalho da CPA é de suma importância para o aprimoramento da gestão, pois novos cenários têm se apresentado na educação superior, e as IESs necessitam constantemente buscar alternativas e métodos para a melhoria de sua estratégia e atingimento de metas. Conforme Mintzberg et al. (2006), as metas e os objetivos estabelecem o que vai ser atingido e quando os resultados do Plano Estratégico devem ser atingidos.

Um dos processos fundamentais da gestão acadêmica é a constituição do Plano de Desenvolvimento Institucional (PDI), exigido conforme Art. 16 do Decreto 5773. O PDI tem propósitos semelhantes ao plano estratégico, sendo o instrumento de gestão que considera a identidade da IES, no que diz respeito à filosofia de trabalho, à missão, às diretrizes pedagógicas, à estrutura organizacional e às atividades acadêmicas que desenvolve e/ou pretende desenvolver (BRASIL, 2006). Elaborado para longo prazo, o PDI traz em sua composição os objetivos e metas que a IES se compromete a realizar durante esse período, de modo a assegurar que o seu desenvolvimento se dê respeitando os critérios mínimos de qualidade exigidos pelo MEC. Nesse sentido, o PDI representa uma carta de compromisso firmada entre a instituição e o MEC.

A profissionalização das IESs encontra-se na estruturação, na articulação e no pensamento sistêmico entre o PDI, o PPI (Projeto Pedagógico Institucional) e o PPC (Projeto Pedagógico do Curso), podendo, assim, garantir resultados mais efetivos da sua gestão. Pode-se considerar que o PDI é uma forma de planejar suas ações. Portanto, 
a partir deste, a instituição direciona seus esforços para desencadear o processo de planejamento e definição de suas estratégias. Reforçando a importância do planejamento e da avaliação, o novo instrumento de avaliação institucional externa, definido em 2014, traz em sua essência a preocupação pertinente da articulação entre esses processos, visando a uma gestão institucional sustentável e que preze pela qualidade da educação superior.

\section{Método de pesquisa}

Tendo em vista o objetivo geral de compreender como ocorre a articulação entre a autoavaliação nas IESs e os processos de planejamento, este estudo foi desenvolvido por meio de pesquisa exploratória, que possibilita prover a compreensão do problema enfrentado pelo pesquisador. Malhotra (2001) afirma que a pesquisa exploratória é usada em casos nos quais é necessário definir o problema com maior precisão, identificar cursos relevantes de ação ou obter dados adicionais antes que se possa desenvolver uma abordagem.

Foi utilizado o procedimento de pesquisa qualitativa de abordagem direta, tendo como técnica essencial as entrevistas em profundidade. Para Malhotra (2001), a entrevista em profundidade é não estruturada e pessoal e um único respondente é testado por um entrevistador capacitado para descobrir motivações, crenças, atitudes e sensações subjacentes sobre um tópico. Uma abordagem direta não é disfarçada, ou seja, o objetivo do projeto é revelado aos respondentes.

Com relação à amostragem, utilizou-se a técnica não probabilística por julgamento, que consiste em lidar com uma amostra em que os elementos são selecionados com base no julgamento do pesquisador. Este, exercendo seu julgamento ou aplicando sua experiência, escolhe os elementos a serem incluídos na amostra, pois os considera representativos da população de interesse, ou apropriados por algum outro motivo (Malhotra, 2001).

O campo empírico foram as Instituições de Educação Superior (IESs), e o critério para a amostra constituiu-se de faculdades e/ou universidades particulares e públicas que tivessem tradição e impacto na sua comunidade, situadas no Estado do Rio Grande do Sul. A escolha propôs determinar uma amostra de instituições privadas e públicas, a fim de observar diferentes percepções dos pesquisados. Sendo:

- Instituição A - universidade privada - entrevistado 1: coordenador da CPA; entrevistado 2: responsável pelo planejamento.

- Instituição B - universidade pública - entrevistado 3: coordenador da CPA; entrevistado 4: responsável pelo planejamento.

- Instituição C - universidade privada - entrevistado 5: coordenador da CPA; entrevistado 6: responsável pelo planejamento 
- Instituição D - faculdade privada - entrevistado 7: coordenador da CPA. entrevistado 8: responsável pelo planejamento.

Utilizou-se a estratégia de análise de conteúdo para melhor compreensão e sistematização dos dados. Essa análise é uma técnica refinada, que exige muita dedicação, paciência e tempo do pesquisador, o qual tem de se valer da intuição, imaginação e criatividade, principalmente na definição de categorias de análise. Para tanto, disciplina, perseverança e rigor são essenciais (FREITAS, CUNHA e MOSCAROLA, 1997).

Embora haja muitos autores que abordem a análise de conteúdo, até mesmo utilizando conceitos diferenciados e diferentes terminologias, para esta pesquisa a conceituação foi de Bardin (2006). Para a autora, a análise de conteúdo consiste em um conjunto de técnicas de análise das comunicações, que utiliza procedimentos sistemáticos e objetivos de descrição do conteúdo das mensagens. O fluxo a seguir (Figura 1) indica o caminho metodológico percorrido.
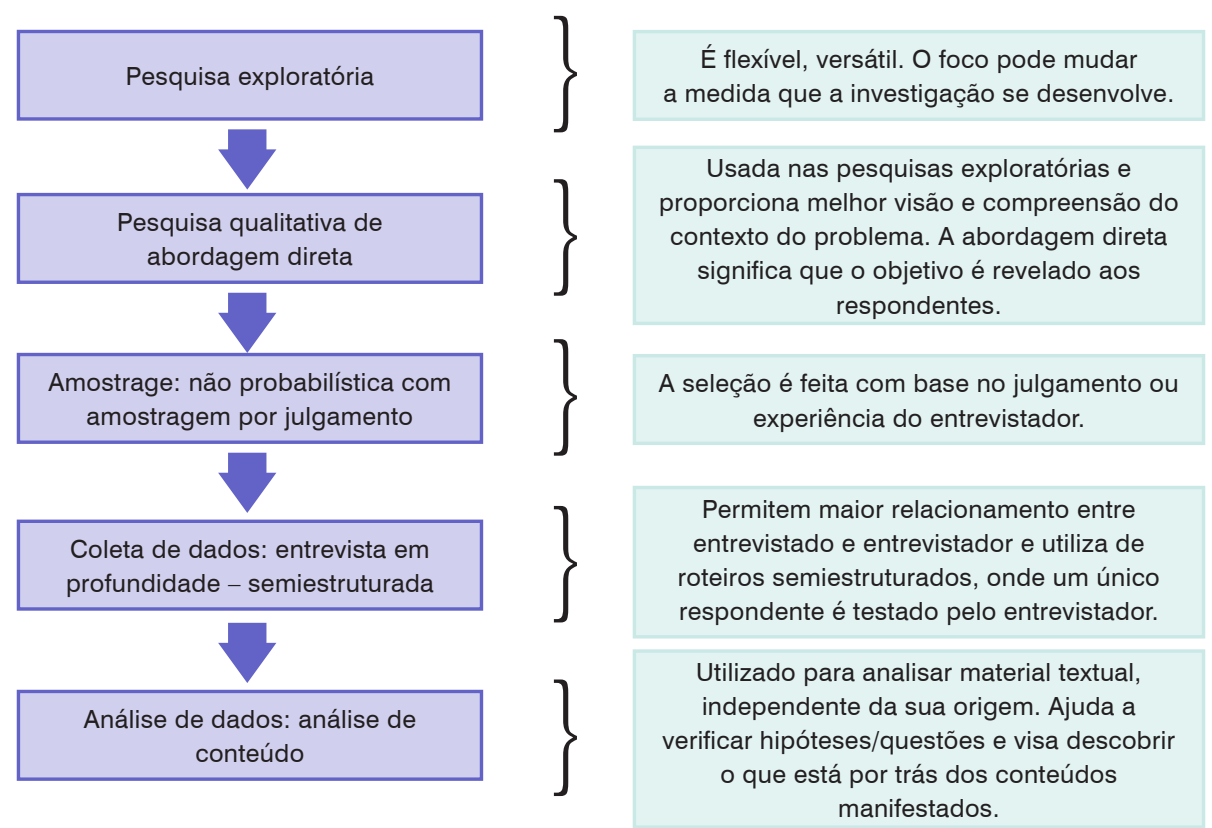

Figura 1. Fluxo do processo metodológico

Fonte: Os autores. 


\section{Resultados}

Os resultados são apresentados de acordo com os objetivos da pesquisa e estão descritos em quatro dimensões: a) Estruturação da CPA; b) Processos de Planejamento e Gestão das IESs; c) Articulação entre Avaliação Institucional e Planejamento; e d) Desenvolvimento das IESs a partir dos resultados de autoavaliação.

\section{a) Estruturação da CPA - Comissão Própria de Avaliação}

A estrutura da CPA das IESs entrevistadas é muito semelhante, tendo em vista seu papel legal, pois o artigo 11 da Lei no 10.861, de 14 de abril de 2004, que institui o Sistema Nacional de Avaliação da Educação Superior (Sinaes), define que deve haver a participação de todos os segmentos da comunidade universitária e da sociedade civil organizada, sendo vedada a composição que privilegie a maioria absoluta de um dos segmentos. Dessa forma, a estrutura das IESs atende à lei, e o que as diferencia é o número de membros e a periodicidade das reuniões. A instituição A possui 17 membros e faz reuniões mensais. Os processos de avaliação institucional são coordenados pela Comissão Própria de Avaliação (CPA), com apoio da Comissão Técnica de Avaliação (CTA). No total, na instituição B, são 17 membros também, com pessoas de diversas áreas e que realizam reuniões semanais, em virtude da reestruturação da CPA. A intuição C possui 15 membros e faz reuniões mensais. Já a instituição D possui 11 membros e faz reuniões quatro vezes ao ano. Com exceção da instituição $\mathrm{D}$, as demais possuem informações em seus sites sobre a estrutura da autoavaliação, sobre a Lei 10.861 e sobre a composição dos membros da CPA. As instituições A, B e C ainda declaram seus pressupostos, atividades e ações de qualificação das equipes.

As avaliações institucionais em todas as IESs pesquisadas são respondidas via portal do aluno, e são gerados relatórios que são estratificados pelas Comissões de Avaliação que entregam para a reitoria, áreas pertinentes e coordenações. Destaca-se que a instituição C desenvolve o processo de avaliação interna desde 1996. Também a instituição A e B informam que faziam autoavaliação mesmo antes da Lei do Sinaes, porém não citaram o ano de início.

As opiniões foram diversas quanto à compreensão de como as áreas das IESs percebem a importância da CPA na gestão institucional. Para o entrevistado 1, da instituição A, o processo de avaliação institucional é mais perceptível pelas áreas acadêmicas, e os alunos não percebem seu valor. Muitas vezes, segundo ele, o acadêmico percebe mais em função da necessidade de relatórios para as avaliações externas. Para o entrevistado 3, da instituição B, a importância da CPA para a IES vem aumentando gradativamente, ao longo do tempo. Durante um período, a CPA teve uma função mais de regulação do que propriamente de avaliação". O entrevistado 5, da instituição C, responde 
que as pessoas veem muito pouco a importância da CPA. Porém, observa que o papel da CPA provocou melhorias na IES. O entrevistado 7, da instituição D, afirma: "Acho que as áreas não veem a importância da CPA para a melhoria da gestão. Apenas algumas áreas percebem”.

Percebe-se que todas as IESs avançaram muito a respeito da autoavaliação e atuação da CPA. No entanto, é perceptível que se encontram em fase de amadurecimento os processos de avaliação institucional. Na percepção dos entrevistados, o maior desafio é a disseminação dos resultados, bem como a utilização dos dados, referentes às manifestações nas avaliações para melhoria dos processos de gestão. De qualquer maneira, todas as IESs expõem os resultados das avaliações no Portal do Aluno, para que haja uma melhor disseminação do que foi coletado e das ações tomadas.

\section{b) Processos de planejamento e gestão}

Observou-se que as instituições pesquisadas apresentam áreas específicas, nas quais são determinadas, analisadas e acompanhadas as estratégias da instituição, utilizando-se a metodologia de Planejamento Estratégico ou do PDI. Portanto, tais áreas são indutoras das ações estratégicas das IESs. Apenas uma dentre as três instituições avaliadas instituição B - não possui o Planejamento Estratégico como ferramenta de gestão, mas sim o PDI como direcionador de seus planos. As demais utilizam as metodologias do Planejamento Estratégico vinculadas também ao PDI. Desde 1995, a instituição A realiza o Planejamento Estratégico. Anteriormente, era a pró-reitoria a responsável pelas atividades relativas ao assunto; atualmente, foi criada uma Assessoria de Planejamento. Na instituição C, a reitoria também é responsável pelo Planejamento Estratégico, e nas revisões há participação de várias áreas, incluindo um membro da CPA. Já a instituição D segue as diretrizes do Planejamento Estratégico da sua mantenedora, a qual detém a responsabilidade, por meio da Assessoria de Planejamento, de elaborar a metodologia e conduzir todas as atividades de revisão de objetivos, metas e do orçamento anual, cabendo à IES determinar suas metas financeiras e negociar com a mantenedora.

Ao longo das entrevistas, ficou evidente que a grande dificuldade está no acompanhamento e monitoramento dos planos. As instituições A e B fazem referência ao Ciclo PDCA. O Ciclo PDCA significa: (P) Plan: planejar, (D) Do: fazer, (D) Check: (V) verificar, (A) Action: Agir. O entrevistado 1, da instituição A, assegura que precisa do apoio dos coordenadores de curso para dar andamento às ações relativas à autoavaliação. Segundo ele, "este processo de acompanhar não é diferente do PDCA". O entrevistado 2, da mesma instituição, cita o PDCA para método de aprendizado e melhoria de processos, e ainda afirma que um dos problemas que dificultam o acompanhamento das ações pode ser o fato de as pessoas não gostarem de ser controladas. Essa declaração alinha-se ao que Kaplan e Norton (2008, p. 35) afirmam: 
O planejamento da estratégia no nível corporativo, ou da empresa como um todo, tem sido objeto de muitas críticas, como sendo burocrático, do tipo comando e controle, inflexível, hierárquico e até autoritário. Não obstante as acusações e queixas de que é alvo, o planejamento estratégico ainda é a ferramenta gerencial favorita dos altos executivos.

O entrevistado 4, da instituição B, declara que eles não conseguem aplicar o PDCA e acompanhá-lo efetivamente, mas possuem os comitês internos que avaliam as ações. Nota-se que os executivos têm percebido a importância do PDCA para planejamento, análise e acompanhamento de seus planos, simultaneamente com outras ferramentas.

Finalmente, sobre as áreas de planejamento, todos os entrevistados citaram que suas instituições concordam sobre sua importância, tendo em vista o papel fundamental de alinhar as diretrizes. O entrevistado 6, da instituição C, enfatizou que as áreas da IES valorizam muito as atividades de planejamento, e já está estabelecida uma cultura. Para o entrevistado 8, da instituição $\mathrm{D}$, os processos de planejamento já fazem parte da realidade, e as áreas contribuem e participam da construção, especialmente na fase de orçamento.

Além do processo de Planejamento Estratégico, vale destacar que as instituições entrevistadas seguem as diretrizes para elaboração do PDI; contudo, há liberdade para criá-los da forma mais adequada às suas realidades. O Decreto $\mathrm{n}^{\circ}$ 5.773/06, Art. 16, declara os elementos mínimos que o PDI deve conter, podendo este ser considerado o coração da instituição, uma vez que, mesmo que a IES tenha Planejamento Estratégico, o documento a ser apresentado oficialmente é o PDI.

\section{c) Articulação entre Avaliação Institucional e planejamento}

Uma pergunta-chave foi feita para todos os entrevistados: se na opinião deles havia articulação entre a CPA e o Planejamento Estratégico/PDI. As respostas revelaram que a articulação entre esses dois processos ainda está longe de ser a ideal. Para a instituição A, uma portaria estabelece que o coordenador da CPA seja o mesmo coordenador da assessoria de planejamento. Segundo o entrevistado 1, da instituição A, a ideia é que a CPA subsidie o planejamento em diversos níveis. Para ele, "é difícil responder sim ou não. Em certa medida, há, mas tem muitas coisas para melhorar. Há muitos anos, este é o objetivo da IES". O entrevistado 2, da mesma instituição, declara que o desafio é alinhar os planos da IES: Planejamento Estratégico, Plano de Gestão da reitoria e PDI, pois os cronogramas muitas vezes não batem. Ele diz ainda que a articulação entre autoavaliação institucional e processo de Planejamento Estratégico tem de avançar. Esse entrevistado, bem como o entrevistado 5, da instituição C, afirma que a extensão do documento pode dificultar a articulação. 
Para o entrevistado 3, da instituição B, durante a construção do PDI foram utilizadas informações provenientes das autoavaliações e ocorreu comunicação intensa entre CPA e reitoria e pró-reitorias, mas declara que precisam evoluir para algo que seja mais automático, com resultados consistentes para poder fazer um planejamento melhor. Segundo o entrevistado 4, da instituição B, não é uma articulação natural e sistêmica, e ocorre mais quando há necessidades pontuais. O entrevistado 6 , da instituição $\mathrm{C}$, confessa que existe articulação quando o relatório chega para a reitoria, mas não existe uma relação mais fina. O entrevistado 7 , da instituição $D$, diz que há articulação, pois os relatórios são levados para os gestores e para o diretor-geral e este faz uso das informações para a tomada de decisão. Já o entrevistado 8, da mesma instituição, declara que as informações recebidas da CPA são usadas como subsídios para a elaboração do Planejamento Estratégico e orçamentário.

O novo instrumento de avaliação institucional externa, publicado pelo Inep/MEC, em 2014, enfatiza a necessidade de haver uma articulação e sincronicidade entre a avaliação e o planejamento da IES. Esse fato justifica-se quando se observam os indicadores do Eixo 1, denominado Planejamento e Avaliação Institucional. O primeiro indicador desse eixo é o 1.1, Evolução Institucional, analisado a partir dos processos de Planejamento e Avaliação Institucional, fato que demonstra a preocupação em relatar o desenvolvimento acadêmico da IES e sua concepção, e não simplesmente atender a um requisito. $\mathrm{O}$ alinhamento com o Relato Institucional comprova um enfoque na gestão, ou seja, nesse caso, a autoavaliação pode, de fato, subsidiar a gestão e a tomada de decisão. Sobretudo, o documento Relato Institucional ganhou ênfase, constituindo-se assim em um instrumento de análise dos processos avaliativos da própria IES (BRASIL, 2014).

\section{d) Desenvolvimento das IESs a partir dos resultados de autoavaliação}

Independentemente da limitada articulação entre autoavaliação e planejamento, inúmeras melhorias são realizadas para a comunidade acadêmica. Os entrevistados foram unânimes em afirmar que houve progressos importantes que se refletem diretamente na qualidade da educação e também na infraestrutura de suas instituições. Três das IESs entrevistadas (A, C, D) narram que muitas vezes os alunos não conseguem associar as melhorias ocorridas com o trabalho da CPA e, em muitos casos, a própria CPA é desconhecida pela comunidade acadêmica. Para o entrevistado 5, da instituição C, com o crescimento das redes sociais, os estudantes preferem socializar seus comentários via Facebook ou, em alguns casos, vão diretamente à Ouvidoria Institucional, fato que ofusca a atuação da CPA. Essa declaração merece destaque, uma vez que o papel dos membros da CPA é justamente fazer um trabalho conjunto, articulando as informações obtidas pelas redes sociais, pela Ouvidoria e pela autoavaliação. Não existindo essa sintonia, as ações tornam-se isoladas e pontuais. 
As quatro IESs pesquisadas relatam melhorias de infraestrutura como ponto alto nas últimas avaliações. Foram melhorias de tecnologia, ar-condicionado e tomadas elétricas, fato que evidencia a exigência cada vez maior de acesso à internet para pesquisas em sala de aula. Alguns exemplos: instituição A colocou data shows em todas as salas de aula; a instituição C investiu na rede elétrica e geradores; e a D investiu na rede de wireless. Segundo os entrevistados, as solicitações provenientes da autoavaliação não conseguem ser realizadas tão rapidamente como a comunidade acadêmica quer, já que envolvem grandes investimentos. Além dos aspectos de infraestrutura, os entrevistados relatam as melhorias nos processos acadêmicos, seja de metodologias, Plano de Curso (PPC), formação continuada dos professores e qualidade de ensino.

Importante observar que a autoavaliação é de fato insumo para a melhoria contínua das IESs, de acordo com o Sinaes, 2009, p. 96:

A avaliação educativa distingue-se do mero controle, pois seus processos de questionamento, conhecimento e julgamento se propõem principalmente a melhorar o cumprimento dos compromissos institucionais, por meio da elevação da consciência pedagógica e da capacidade profissional dos docentes, da produção de conhecimentos e da análise crítica do conjunto de práticas e dinâmicas institucionais.

O novo instrumento de avaliação institucional, por buscar atender à diversidade do sistema de educação superior e respeitar a identidade da IES, apresenta algumas palavras antes muito mais mencionadas nas áreas de Administração do que na de Educação. Porém, felizmente, no novo instrumento, é possível ver palavras como melhoria e evolução. Contidas no instrumento, estas tornam transparente a importância do desenvolvimento, do progresso, do crescimento das IESs e não simplesmente o atendimento a itens e ganho de pontos em uma escala.

\section{Considerações finais}

Ao se aprofundar a leitura sobre o Sinaes, percebe-se que há ainda autores que consideram a avaliação apenas uma forma de criar rankings dos resultados. Apesar disso, observa-se que esse sistema tem como princípio central a integração e a participação, a fim de que haja uma construção coletiva entre os atores da comunidade acadêmica, visando à melhoria da qualidade do ensino. Para tanto, o Sistema Nacional de Avaliação busca integrar as dimensões da avaliação externa e interna.

Contudo, nesta pesquisa, o foco é a autoavaliação. Não se pode perder de vista que esta é uma forma de obter informações relevantes acerca da Instituição de Educação Superior, ou seja, é um olhar para dentro. Dessa forma, 
tem a possibilidade de transformar as informações oriundas de alunos, professores e técnicos administrativos em melhorias de infraestrutura, projetos, mudanças nos currículos, entre outros pontos.

Também foram pesquisados os processos relativos ao Planejamento Estratégico e ao Plano de Desenvolvimento Institucional. Nas instituições pesquisadas, apenas uma delas não aplicava a metodologia do Planejamento Estratégico, mas utilizava o PDI. Embora a IES não apresentasse um Planejamento Estratégico nos moldes conhecidos nas bibliografias, proferido por autores como Mintzberg, Kaplan e Norton, ficou evidente que o PDI é um direcionador das estratégias e dos planos dessa instituição.

As demais instituições entrevistadas possuem o Planejamento Estratégico como método de apoio para criação da sua missão, visão, valores, políticas, objetivos e metas. Para estas, o Planejamento Estratégico e as áreas responsáveis por sua condução são percebidos internamente com olhares positivos e proporcionam uma condução e acompanhamento dos objetivos e metas de forma abrangente e coordenada, gerando resultados satisfatórios, até então, para as instituições.

Ficou evidente que a articulação entre o planejamento e a autoavaliação ainda está longe de ser o ideal. Apenas uma das quatro instituições apresentou unificação entre a área que gerencia as Avaliações Internas e a Assessoria de Planejamento. Nas demais, a articulação é apenas em época de atividades de planejamento e autoavaliação, ou exclusivamente durante a entrega dos relatórios de autoavaliação para a reitoria ou direções de núcleos.

Um dos motivos que podem ocasionar essa dificuldade de sincronia pode ser o tamanho dos relatórios. Para alguns entrevistados, a extensão do relatório final, documento oficial exigido pelo Inep/MEC no primeiro trimestre de cada ano, transforma a leitura em algo demorado e trabalhoso. Cabe aos responsáveis pela autoavaliação, nesse caso a CPA, e às áreas de planejamento criar métodos e padrões para transformar esses conteúdos em materiais consistentes, porém sucintos, que possam servir como subsídios para as análises do Planejamento Estratégico e do PDI. Ou, ainda, determinar sistemas informatizados articulados e práticos, pois neste estudo observa-se que nem todas as IESs possuem softwares que organizam e transformam os dados coletados das autoavaliações em informações relevantes para a análise e tomada de decisão.

No sentido de contribuir para uma maior efetividade dos resultados deste estudo, propõe-se o fluxo a seguir (Figura 2), com uma visão sistêmica e sequenciada da análise dos resultados de autoavaliação até a definição de objetivos e iniciativas estratégicas por parte da IES.

O relatório resumido a ser elaborado pela CPA tem a intenção de facilitar o entendimento de quem analisa, sendo composto por reclamações, pontos fortes, elogios e reincidências. Sugere-se que, durante a metodologia de revisão do Planejamento Estratégico ou do PDI, exista uma articulação entre os resultados da autoavaliação e a fase do planejamento, chamada Análise Interna. Assim, as informações relativas à autoavalição apoiam o diagnóstico 


\section{Fluxo da Articulação}

\section{Fluxo após Autoavaliação}

Criação pela CPA de 1ํ Relatório Resumido.

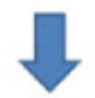

Análise dos resultados pela CPA e demais áreas envolvidas como: reitoria, coordenadores, diretores.

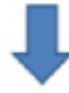

Análise e debates durante encontro com grupo de responsáveis envolvidos.

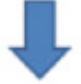

Relatório resumido com tópicos principais. Subsídio para análise de cenários.

\section{Fluxo Planejamento Estratégico/PDI}

Definição das Diretrizes Estratégicas, Revisão de Políticas, Missão e Visão.

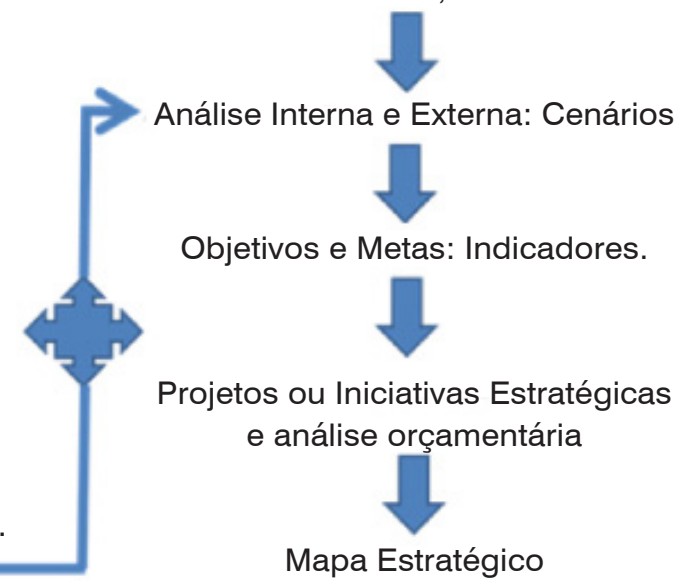

Figura 2. Fluxo da articulação Fonte: Os autores.

interno para o planejamento. Esses resultados refletem, então, um dos insumos para a determinação de objetivos, metas, indicadores e, por fim, projetos, orçamento e iniciativas estratégicas.

Embora essa metodologia proposta pareça ser factível, durante as entrevistas com os oito gestores, evidenciou-se não haver um padrão para a aplicação dos resultados da autoavaliação que fosse sistemático e que pudesse oportunizar um acompanhamento posterior, ou seja, a articulação ainda precisa de muito amadurecimento dos gestores.

Contudo, apesar da ausência de sincronicidade, não se pode esquecer que o Ministério da Educação, através do novo instrumento de avaliação institucional, dá sinais evidentes da preocupação que envolve os processos de avaliação internos ou externos, no sentido de contribuírem efetivamente para o planejamento e para a gestão institucional, tendo como pressuposto a melhoria da qualidade da educação superior. 


\section{Referências}

BARDIN, Laurence. Análise de conteúdo. Lisboa: Edições 70, 2006.

BRASIL. Ministério da Educação (MEC). Instituto Nacional de Estudos e Pesquisas Educacionais Anísio Teixeira (INEP). Portaria n⿳0 161, de 16 de abril de 2013. Designa composição da comissão para revisão dos instrumentos de avaliação institucional e de polo de apoio presencial na modalidade a distância e para escolas de governo, no âmbito do Sistema Nacional de Avaliação de Educação Superior - Sinaes. Diário Oficial [da] República Federativa do Brasil, Brasília, DF, 17 abr. 2013 , Seção 2, p. 26.

. Portaria no 92, de 31 de janeiro de 2014. Aprova, em extrato, os indicadores do instrumento de avaliação institucional externa para os atos de credenciamento, recredenciamento e transformação de organização acadêmica, modalidade presencial, do Sinaes. Diário Oficial [da] República Federativa do Brasil, Brasília, DF, 4 fev. 2014. Brasília, Seção 1, p. 5.

. SINAES - Sistema Nacional de Avaliação da Educação Superior: da concepção à regulamentação. 5. ed. Brasília: Instituto Nacional de Estudos e Pesquisas Educacionais Anísio Teixeira, 2009.

. Lei no 10.861, de 14 de abril de 2004. Institui o Sistema Nacional de Avaliação da Educação Superior - Sinaes e dá outras providências. Diário Oficial [da] República Federativa do Brasil, Brasília, DF, 5 abr. 2004.

. Decreto no 5.773, de 9 de maio de 2006. Dispõe sobre o exercício das funções de regulação, supervisão e avaliação de instituições de educação superior e cursos superiores de graduação e sequenciais no sistema federal de ensino. Diário Oficial [da] República Federativa do Brasil, Brasília, DF, 10 maio 2006, p. 6, c. 1. Disponível em: <http:/www.planalto.gov.br/CCIVIL/_Ato20042006/2006/Decreto/D5773.htm>. Acesso em?

CATANI, Afrânio; OLIVEIRA, João Ferreira; DOURADO, Luiz Fernandes. A política de avaliação da educação superior no Brasil em questão. Avaliação - Revista da Avaliação Superior, Campinas, v. 6, n. 4, p. 7-26, dez. 2001.

CREUTZBERG, Marion; CASARTELLI, Alan. A autoavaliação e o planejamento da IES: como aproximar? Avaliação institucional em IES comunitárias. Porto Alegre: EdiPUCRS, 2014. p. 138-152.

DIAS SOBRINHO, José. Avaliação e transformações da educação superior brasileira (1995-2009): do provão ao Sinaes. Avaliação Revista da Avaliação Superior, Campinas; v. 15, n. 1, p. 195-224, mar. 2010.

. Avaliação institucional. Marcos teóricos e políticos. 1995. Disponível em: <http://educa.fcc.org.br/pdf/aval/v01n01/ v01n01a03.pdf>. Acesso em: 15 jan. 2014.

. Qualidade, Avaliação: do Sinaes a índices. Avaliação - Revista da Avaliação da Educação Superior, Campinas, v. 13, n. 3, p. 817-825, nov. 2008.

FREITAS, Henrique; CUNHA, Raquel; MOSCAROLA, Jean. Aplicação de sistemas de software para auxílio na análise de conteúdo. Revista de Administração da USP, v. 32, n. 3, p. 97-109, 1997.

INSTITUTO NACIONAL de Estudos e Pesquisas Educacionais Anísio Teixeira (INEP). SINAES. Brasília, DF, Disponível em: < http:// portal.inep.gov.br/superior-SINAES>. Acesso em: 11 jan. 2014. 
KAPLAN, Robert; NORTON, David. A execução premium: a obtenção de vantagem competitiva através do vínculo da estratégia com as operações do negócio. Rio de Janeiro: Campus, 2008.

MALHOTRA, Naresh. Pesquisa de marketing: uma orientação aplicada. 3. ed. Porto Alegre: Bookman, 2001.

MINTZBERG, Henry et al. O processo da estratégia: conceitos, contextos e casos selecionados. 4. ed. Porto Alegre: Bookman, 2006.

SCAGLIONE, Vera; Lúcia. COSTA, Marcelo. Avaliação da educação superior e a gestão universitária: padrões de qualidade definidos pelas instituições de ensino superior, pelo MEC e pela sociedade, incluindo Enade, IDD, CPG e IGC. CONGRESSO DE GESTÃO UNIVERSITÁRIA, XI., "Gestão universitária, Cooperação Internacional e Compromisso Social”, Florianópolis, 2011.

SCHWARTZMAN, Simon. Os desafios da educação no Brasil. Rio de Janeiro: Nova Fronteira, 2005.

ZAINKO, Maria Amélia. Avaliação da educação superior no Brasil: processo de construção histórica. Avaliação - Revista da Avaliação Superior, Campinas, Sorocaba, v. 13, n. 3, p. 827-831, nov. 2008.

Recebido em: julho/2017

Aceito em: outubro/2017

\section{Endereço para correspondência:}

Av. Ipiranga, 6681 - Partenon

90619-900 Porto Alegre, RS, Brasil

<gio_bruschi@msn.com> 